\title{
Transformational Leadership and Individual Creativity: The Mediating Role of Structural Empowerment
}

\author{
Salem Mohamed A. Mansur \\ School of Economics and Management \\ Beihang University, Beijing, China \\ HTIs, Gasser Ben Ghachir , Libya \\ Salemalmashi2015@yahoo.com
}

\author{
Guozhu Jia \\ School of Economics and Management \\ Beihang University, Beijing, China \\ jiaguozhu@buaa.edu.cn
}

\begin{abstract}
This paper investigates the mediating role of structural empowerment between transformational leadership (TLs) and individual creativity. A sample based data was collected from 450 faculty members from higher technical institutions (HTIs) of Libya. The findings indicate that TL and structural empowerment positively affect individual creativity. The findings also indicate that structural empowerment partially mediates the relationship between TLs and individual creativity. The findings will contribute to transformational leadership, empowerment and creativity literature in a part of the world in which limited knowledge is available in this area. The results are valuable for Libyan' decision makers in HTIs so that they can enrich their agenda in designing programs to develop managers' leadership skills and enhance creative behaviors of their employees. The results of this research contribute to the literature on individual creativity in education management literature by enhancing the understanding of the influences of structural empowerment and transformational leadership on individual creativity among faculty members. This study offers important policy insight for higher technical leadership who seek to increase individual creativity among faculty members.
\end{abstract}

Keywords-Transformational Leadership; Structural Empowerment; Individual creativity; higher technical institutes; Libya

\section{INTRODUCTION}

Many scholars contend that the main role of leadership in contemporary organizations in the management of creativity, encouragement and supported it. Emerging studies are calling to change the managerial approach and move away from the traditional approach of trial and error based leadership towards the creative approach [1]. There is a consensus among scholars and practitioners that the capabilities of creative employees in organizations are affected by the prevailing pattern of leadership, thus leadership is one of the fundamental aspects affecting the organizational creativity [2] and plays a crucial role in promoting creativity [3]. To support this view, Bel, argues that leaders representing the main pillar in the creativity management in organizations by either encouraging the creativity or discouraging it [4]. In this view, researchers have paid their attention to TLs. Many scholars, practitioners, and administrators have called for more efforts to adapt to the environment and to respond to the rapid changes facing by them. Transformational leaders (TLs) work to achieve their goals using a variety of methods and management tools that facilitate and support the principles developed based upon it. Among the most famous methods is empowering employees. Employee empowerment requires tremendous efforts in terms of restructuring an organization and its processes, systems and organizational climate to build empowerment and be able to achieve concrete outcomes. The TLs is a primarily dependent on teamwork to empower their followers to act and make decisions, and give them the power that enables them to be creative in their work. Empowerment is one of the important methods and requirements used by transformational leaders to achieve participation and cooperation with their followers and emphasize the strong commitment towards achieving the goals [5].

\section{BACKGROUND}

\section{A. Relationship between transformational leadership and individual creativity}

The TLs can be defined as a leader's behavior that inspires his/her followers to perform beyond expectations and transcending self-interest to the interest of the organization [6]. Its dimensions are (1) idealized attributes, (2) idealized behaviors, represents a set of attributes and behaviors which make the leader as a role model by subordinates, (3) Individualized consideration, it focuses on the communication and behaviors between the leader and his/her subordinates [7], (4) Intellectual stimulation, is related to the ability of the leader to convince subordinates to need to abandon old ways of thinking and adopt creative ways [8], (5) Inspirational motivation means the leaders' ability to articulate a vision while demonstrating optimism and enthusiasm [9]. The TLs dimensions were and still are the field of the researchers to know its relationship and influence on a lot of behaviors, such as organizational learning, job satisfaction, turnover etc. With regard to its relationship with creativity, extant research has shown contradictory conclusions; ranging from positive, weak and negative relationship. The findings of some researchers show that leadership, in general, has a significant positive relationship on individual creativity $[10 ; 2 ; 11 ; 12]$. The TLs enhances creativity by providing adequate support to followers 
[13]. TLs appreciate behaviors that create an environment that generate new ideas and solutions to organizational problems. Although TLs recognize that creativity and change associated with risks, but they continue working, challenge and learn from their mistakes, as they learn from their successes. Thus, we hypothesized that:

H1: TLs dimensions has a positive impact on individual creativity among faculty members in the western region of Libya.

\section{B. Relationship between transformational leadership and structural empowerment}

Structural empowerment refers to making amendments in each of the policies, procedures and organizational structures aimed to grant employees a high degree of autonomy in the organizational decision-making process and participation of the followers in the sources of power, knowledge, rewards, information, resources, and opportunity [14]. TLs work to achieve organizational goals using a variety of methods and management tools that facilitate and support the principles; among the most famous of these methods is employee empowerment [15]. Many studies of organizational leadership emphasize the impact of leadership behavior on empowerment, and it is the modern way to increase organizational effectiveness [16]. Empowerment requires tremendous efforts in terms of restructuring the organization and its processes, systems and organizational climate to build empowerment able achieve concrete outcomes.

The TLs mainly dependents on teamwork and working to empower their followers to make decisions and give them powers to enable them to do their work. Thus, we hypothesized that:

H2: TLs a positive impact on structural empowerment among faculty members in the western region of Libya.

\section{Relationship between structural empowerment and individual creativity}

The empowerment commits employees towards achieving organizational goals [8]. Today's organizations cannot be limited to the cooperation of a small group of employees, but should include all personnel and provide opportunities for doing good jobs. Kanter and Laschinger identified six dimensions for structural empowerment: information, support, resources, opportunity, formal power and informal power $[17,18]$. These six dimensions constitute the well-established multidimensional construct for structural empowerment throughout literature.

A study by [9] showed that jobs which have the diversity of tasks and autonomy and a low level of routine and regulations promotes a sense of empowerment among employees. Leaders who support the democratic culture of organizations will lead to highest production levels of creative performance of employee compared with hierarchical working structures. Literature suggests that the levels of the empowerment in the organization depend on the nature of the structural conditions in the work environment. Thus, we hypothesized that:
H3: Structural empowerment has a positive impact on individual creativity among faculty members in the western region of Libya.

\section{METHOD}

The data for this study was collected from a sample of 450 HTIs' faculty members in western region of Libya. The participants completed a questionnaire consisting of several different scales which evaluate all constructs in the conceptual model of the study. The scales were selected based on their use in literature and possessing acceptable characteristics in terms of content validity and reliability. The TLs was measured by the Multifactor Leadership Questionnaire (MLQ), consisting of 20 items [19]. The structural empowerment was measured with 19 items by the instrument developed by [18]. Individual creativity was measured with 12 items by the scales developed by [20,21]. All items were based on a 5-point Likert type scale, ranging from 1 (strongly disagree) to 5 (strongly agree).

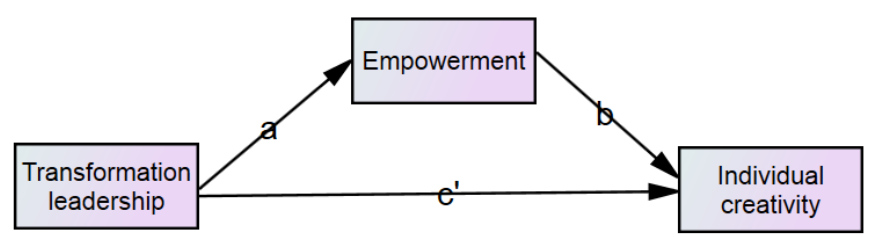

Fig. 1. Conceptual model of the study

The age of $26.1 \%$ respondents were below 40 years, $56.2 \%$ were between $41-50$ years and $17.7 \%$ were above 51 years. The $75.1 \%$ of the participants hold Master degrees while the remaining $24.9 \%$ hold $\mathrm{PhD}$. As for scientific titles, $49 \%$, $37.8 \%, 12.8 \%$ and $0.5 \%$ of the participants hold assistant lecturer, lecturer, assistant professor, associate professor titles respectively. There was no full professor in the sample. The $9.1 \%$ of the respondents had 1-5 years' experience, $42.4 \%$ had $6-10$ years of experience, and the remaining $27.7 \%$ and $20.7 \%$ had 11-15 years and over 16 years of work experience respectively.

\section{RESUlts}

All the data were analyzed using SPSS, version 21. The linear regression employed as well as mediation analysis to test the hypotheses following [22]. Descriptive statistics, Cronbach alphas and correlation coefficients of the variables are presented in Table 1. None of the correlations values exceeded .8, indicating no threat of collinearity [23]. The results show that mean value of TLs is below the mid-point of the scale, indicating that faculty members of HEIs in Libya believe that their leaders display low levels of transformational leadership behaviors.

TABLE I. SD, CRONBACH ALPHAS AND CORRELATION MATRIX

\begin{tabular}{|l|c|c|c|c|c|}
\hline Variables & Mean & S .D & $\mathbf{1}$ & $\mathbf{2}$ & $\mathbf{3}$ \\
\hline Transformational Leaders & 2.97 & $.66^{* *}$ & $(.94)$ & & \\
\hline Structural Empowerment & 3.22 & $.72^{* *}$ & $.563^{* * *}$ & $(.91)$ & \\
\hline Individual Creativity & 3.80 & $.41^{* *}$ & $.513^{* * *}$ & $.45^{* * *}$ & $(.77)$ \\
\hline
\end{tabular}


Hypothesis 1 predicted that transformational leadership will be positively related to individual creativity. Our results showed that TLs explains $26 \%$ of the variance in individual creativity, that is $R^{2}=.26$. The results also showed that TLs contributed positively and significantly to individual creativity $(\beta=.51, p<.01)$. Thus, hypothesis 1 is supported.

Our second hypothesis concerned the relationship between TLs and structural empowerment of employees. The results showed that TL explains $31 \%$ of the variance structural empowerment, that is $R^{2}=.31$. The results also showed that TLs contributed positively and significantly to structural empowerment $(\beta=.56, p<.01)$. Therefore, our data confirms the relationship.

The third hypothesis expected a positive relationship between structural empowerment and individual creativity. The results showed that structural empowerment explains $21 \%$ of the variance in individual creativity, that is $R^{2}=.21$. The results also showed that TLs contributed positively and significantly to individual creativity $(\beta=.45, p<.01)$. Hence, the relationship is confirmed.

The hypotheses did not formally address possible relationships between the individual and contextual variables and work-related outcomes. However, the appearance of the conceptual model (see Fig. 1) suggests that recipients' change proactivity may mediate the relationship between the individual and context-related variables and work outcomes.

According to [24], a necessary aspect of a meditational analysis is that (a) the independent variable should be significantly associated with the outcome variable (path c); (b) there should be a significant correlation between the independent variable and the mediator variable (path a). Third, there should be a significant correlation between the mediator variable and the dependent variable (path b), and finally, when controlled for the mediator variable (when the mediator variable is entered in the regression equation describing path c), the correlation in path (a) should no longer be statistically significant and thus be eliminated. This implies that the effect between the independent and the dependent variables unfolds itself through the mediator variable. However, given the multiple causes that exist in social reality, it is unlikely to achieve complete mediation. Therefore, the last condition can be relaxed to 'a significant reduction of the direct effect' rather than a complete elimination of the effect. When this is applicable, one speaks of partial mediation [25, 26].

Our results showed that TLs and empowerment together accounted for $30 \%$ of variance in individual creativity. The results also showed that when we controlled for the mediator variable, the $\beta$ value of TLs decreased from .51 to .37. However, the $\beta$ value of TLs is still significant at .01 . This indicates that empowerment partially mediates the relationship between TLs and individual creativity.

\section{DISCUSSION}

HTIs in Libyan has recently experienced significant growth after the establishment of an independent body with the aim to develop strategies to promote higher technical education to meet the needs of the local market, which currently relies heavily on expatriate to manage and implement development plans in the country. However, this sector remains substandard in the efficiency of its outputs. The purpose of this study was to investigate the relationships among transformational leadership, structural empowerment, and individual creativity amid faculty members in selected HTIs in Libya.

This study also performed mediation analysis to identify the mediating effect of empowerment on the relationship between transformational leadership and individual creativity.

In the first stage, the hypothesis of whether transformational leadership has a positive influence on individual creativity among faculty members in HTIs in Libya was tested. The results show that transformational leadership positively influences individual creativity. Our results suggest that the transformational leadership enhances individual creativity among faculty members. So, our findings are consistent with some previous studies, mostly conducted in Western, developed countries, that also investigated such relationship [10,11,27,28,29].

In the second stage we tested the hypothesis; that transformational leadership has a positive influence on structural empowerment. This hypothesis was also supported.

In the third stage we tested the hypothesis; that structural empowerment has a positive influence on individual creativity. The results indeed confirmed such a relationship. The findings are consistent with several studies that found the positive influence of empowerment on individual creativity.

The final step and the main goal of the study was the examination of the mediation analysis to identify whether structural empowerment mediates the relationship between transformational leadership and individual creativity. The mediation results showed that structural empowerment partially mediates the relationship between transformational leadership and individual creativity. So, transformational leadership has both direct and indirect effect on individual creativity. This finding represents an important contribution to the literature which shows structural empowerment as a crucial structural mechanism through which transformational leadership influences employee creativity. The partial mediation suggests that structural empowerment plays an important role in the relationship between transformational leadership and creativity, where structural empowerment acts as a variable that strengthens the relationship between transformational leadership and creativity. Partial mediation of structural empowerment also indicate that there were many other variables that can play the role of mediator in the relationship between transformational leadership and creativity, and the researcher believes that partial mediation is better in terms of an applied process than fully mediates indicating that the median variable is the only variable that is unique in effect on the strength of the relationship between the independent variable and the dependent variable. Thus, as a result of the partial mediation of structural empowerment in this study, the field becomes wider for interested researchers to conduct studies similar to the discovery of other mediation variables in the same relationship between the variables. 


\section{CONCLUSION}

In contrast to some previous studies which showed a negative relationship between transformational leadership and individual creativity, the findings of the current study showed transformational leadership positively affects individual creativity of employees.

The results also showed the ability of transformational leadership to enhance its role on individual creativity through structural empowerment as a mediator in this relationship, where the study confirmed the partial mediation role of structural empowerment in the relationship between the transformational leadership and individual creativity. Transformational leadership influence on individual creativity, both directly and through structural empowerment, contributes significantly to the enhancement of individual creativity which represents the main source of team creativity and organizational creativity. According to the partial mediation results, structural empowerment explains how transformational leadership is related to individual creativity, this means the faculty members who work with transformational leadership expected to have more access to information, resources, opportunities, and support through the formal and informal power [20,31,32]

The outcomes of this study provide a framework within which HTIs in Libya can embrace transformational leadership strategies to satisfy their prospective employees and students, particularly if they are permitted to operate in an environment that is becoming more deregulated and competitive. It is recommended that the leaders in public institutions in Libya adopt transformational leadership practices as their standard leadership style. The findings of this study can also assist leaders and managers of other sectors in Libya to improve their approach to enable their employees and supporting creative performance. It is clear that this research study has limitations as with other research, which may impact negatively on outcomes.

Although our analysis provides support for the relationship between transformational leadership, empowerment, and creativity, the study design precluded the demonstration of any causal relationships. The study design was a cross-sectional survey design rather than an experimental design so that causality could be inferred. Because data were collected at one point in time, the direction of causality of the relationships examined in this study is not certain. However, this is a common issue in survey research and a limitation to knowledge. An experimental design would have provided a more robust test of the hypothesized causal relationship, but such research in the leadership field is relatively rare ( $\mathrm{Lu}$, 2006). Some of the limitations, however, lead to opportunities for future development and additional research. Further research should be conducted to test the mediation and dependent variables within the organizational context in the relationship with the transformational leadership.

Finally, this study has theoretical implications in the education management literature to develop and verify a theoretical framework for the relationships between the perceptions of transformational leadership, structural empowerment, and individual creativity. This study offers more understanding of the structural empowerment role that underlies this relationship and achieved theoretical contributions in education management literature in Libyan context.

\section{REFERENCE}

[1] García - Morales, V.J., Lloréns - Montes, F.J. and Verdú - Jover, A.J., 2008. The effects of transformational leadership on organizational performance through knowledge and innovation. British journal of management, 19(4), pp.299-319.

[2] Denti, L. and Hemlin, S., 2012. Leadership and innovation in organizations: A systematic review of factors that mediate or moderate the relationship. International Journal of Innovation Management, 16(03), p.1240007.

[3] Amabile, Teresa M., et al. "Leader behaviors and the work environment for creativity: Perceived leader support." The Leadership Quarterly 15.1 (2004): 5-32.

[4] Bel, Roland. "Leadership and innovation: Learning from the best." Global business and organizational excellence 29.2 (2010): 47-60.

[5] Zhu, Weichun, et al. "Relationships between transformational and active transactional leadership and followers' organizational identification: The role of psychological empowerment." Journal of Behavioral and Applied Management 13.3 (2012): 186.

[6] Avolio, Bruce J., Fred O. Walumbwa, and Todd J. Weber. "Leadership: Current theories, research, and future directions." Annual review of psychology 60 (2009): 421-449.

[7] Hoption, Colette, Julian Barling, and Nick Turner. "“It's not you, it's me”: transformational leadership and self-deprecating humor." Leadership \& Organization Development Journal 34.1 (2013): 4-19.

[8] Zhou, Qin, Giles Hirst, and Helen Shipton. "Context matters: Combined influence of participation and intellectual stimulation on the promotion focus-employee creativity relationship." Journal of Organizational Behavior 33.7 (2012): 894-909.

[9] Golden III, John H. Examining Relationships between Transformational Leadership and Employee Creativity and Innovation Performance: The Moderator Effects of Organizational Culture, 2016.

[10] Puccio, Gerard J., Marie Mance, and Mary C. Murdock. Creative leadership: Skills that drive change. Sage Publications, 2010.

[11] Carmeli, Abraham, Roy Gelbard, and Roni Reiter - Palmon. "Leadership, creative problem - solving capacity, and creative performance: The importance of knowledge sharing." Human Resource Management 52.1 (2013): 95-121.

[12] Shin, Shung Jae, and Jing Zhou. "Transformational leadership, conservation, and creativity: Evidence from Korea." Academy of management Journal 46.6 (2003): 703-714.

[13] Cheung, Millissa FY, and Chi-Sum Wong. "Transformational leadership leader support, and employee creativity." Leadership \& Organization Development Journal 32.7 (2011): 656-672.

[14] Francescato, Donata, and Mark S. Aber. "Learning from organizational theory to build organizational empowerment." Journal of Community Psychology 43.6 (2015): 717-738.

[15] Mansur, Salem, and Jia Guozhu. "Transformational Leadership and Organizational Creativity: The Mediating Role of Process Approach Empowerment." DEStech Transactions on Engineering and Technology Research apop (2017).

[16] Bennis, Warren. "Inclusion, Initiatives, and Cooperation of Followers." Organizational Dynamics 27.i1 (1999): 71.

[17] Moss, Kanter R. "When giants learn to dance." Mastering the Challenges of Strategy Management and Careers in the 1990s. Simon and Schuster, 1989.

[18] Laschinger, Heather K. Spence, et al. "Impact of structural and psychological empowerment on job strain in nursing work settings: expanding Kanter's model." Journal of nursing Administration 31.5 (2001): 260-272. 
[19] Bass BM, Avolio BJ. MLQ: multifactor leadership questionnaire: technical report, leader form, rater and scoring key for MLQ (Form 5xshort). Redwood City: Mind Garden; 2000.

[20] Tierney, Pamela, Steven M. Farmer, and George B. Graen. "An examination of leadership and employee creativity: The relevance of traits and relationships." Personnel psychology 52.3 (1999): 591-620.

[21] Hult, G. Tomas M., Robert F. Hurley, and Gary A. Knight. "Innovativeness: Its antecedents and impact on business performance." Industrial marketing management 33.5 (2004): 429-438.

[22] Preacher, Kristopher J., and Andrew F. Hayes. "SPSS and SAS procedures for estimating indirect effects in simple mediation models." Behavior research methods, instruments, \& computers 36.4 (2004).

[23] Hair, Joseph F., et al. Multivariate data analysis. Vol. 5. No. 3. Upper Saddle River, NJ: Prentice hall, 1998.

[24] Baron, R.M. and Kenny, D.A., 1986. The moderator-mediator variable distinction in social psychological research: Conceptual, strategic, and statistical considerations. Journal of personality and social psychology, 51(6), p.1173.

[25] Ahmad, B. A., "A change management perspective on public sector reform”, PhD Dissertation, Beihang University, China, 2018.

[26] Ahmad, B. A., \& Cheng, Zh. "The role of change content, context, process and leadership in understanding employees' commitment to change: The case of public organizations in Kurdistan Region of Iraq." Public Personnel Management, 2018.
[27] Wang, Peng, and Joseph C. Rode. "Transformational leadership and follower creativity: The moderating effects of identification with leader and organizational climate." Human relations 63.8 (2010): 1105-1128.

[28] Herrmann, Daniel, and Jrg Felfe. "Moderators of the relationship between leadership style and employee creativity: the role of task novelty and personal initiative." Creativity Research Journal 25.2 (2013): $172-181$.

[29] $\mathrm{Hu}$, Hong, Qin xuan Gu, and Jixiang Chen. "How and when does transformational leadership affect organizational creativity and innovation? Critical review and future directions." Nankai Business Review International 4.2 (2013): 147-166.

[30] Azman Ismail,et al,An Empirical Study of the Relationship between Transformational Leadership, Empowerment and Organizational Commitment.Business and Economics Research Journal Volume 2 . Number 1. 2011,pp. 89-107,ISSN: 1309-2448.

[31] Krishnan VR. Transformational leadership and personal outcomes: empowerment as mediator. Leadership \& Organization Development Journal 2012, 33(6):550-63

[32] Kasasbeh, Emad Ali, Yoshifumi Harada, and Abdullah Bin Osman. "The impact of the transformational leadership in the administrative creativity: An Applicative Study on the industrial companies (Mining and Extraction) in Jordan." International Journal of Academic Research in Business and Social Sciences 4.5 (2014): 382. 